\title{
PERFIL DE BIÓPSIA HEPÁTICA EM PACIENTES EM ACOMPANHAMENTO PÓS- TRANSPLANTE DE FÍGADO EM UM HOSPITAL PEDIÁTRICO
}

\author{
Profile of liver biopsy in monitoring postoperative patients in a pediatric hospital \\ Rogério Rodrigues Vilas Boas', Julio (Cesar) Wiederkher², Alexandra Oliveira Fernandes Conceição², \\ Izabel Cristina Meister Coelho'2, Elizangela Mattos e Silva²
}

\section{RESUMO}

Introdução: Biópsias de fígado são realizadas para avaliar complicações no pós-transplante. Existem pontos a serem esclarecidos quanto à ocorrência de alterações histológicas na população pediátrica e sua relevância na clínica. Objetivo: Analisar achados em biópsia hepática pós-transplante nos pacientes pediátricos atendidos por nosso serviço. Métodos: Foi realizado levantamento dos registros de pacientes que se encontravam em acompanhamento pelo serviço, em dezembro de 2013. Achados histológicos foram distribuídos entre achados de inflamação, rejeição, fibrose, colestase e esteatose. Foram descritas indicações e correlação clínica para os achados. Resultados: Foram obtidos resultados de 105 biópsias de 53 pacientes. Os achados mais comuns relacionaram-se à inflamação (87\%) e fibrose portal (47.2\%). Foi detectado o aumento do número de achados de fibrose em relação ao tempo após o transplante. Proliferação ductular esteve relacionada com complicações graves. Dentre as biópsias indicadas por protocolo, 77,3\% apresentaram alterações com achados, como fibrose, inflamação, rejeição e colestase. Conclusão: Anormalidades foram comuns nesses pacientes, mesmo sem uma forte correlação clínica. São necessários mais estudos quanto à indicação de biópsia protocolar, e os resultados indicam que pode haver vantagem no diagnóstico precoce dessas anormalidades.

Descritores: Transplante de Fígado, Biópsia, Pediatria.

\footnotetext{
Instituição:

${ }^{1}$ Residência Multiprofissional em Saúde da Criança e do Adolescente, Faculdades Pequeno Príncipe - Curitiba/PR

${ }^{2}$ Serviço de Transplante de Fígado - Hospital Pequeno Príncipe Curitiba/PR
}

\section{Correspondência:}

Rogério Rodrigues Vilas Boas

Rua Desembargador Motta, 1070 - CEP 80250-060 - Curitiba/PR

Tel.: (41) 3310-1400

E-mail: rogeriorvb@gmail.com

Recebido em: 10/01/2014

Aceito em: 20/01/2014

\section{INTRODUÇÃO}

O transplante de fígado é uma cirurgia que fornece aos pacientes com doenças hepáticas terminais, a oportunidade de vida longa e saudável. Apesar dos benefícios, podem ocorrer complicações em curto e longo prazo por etiologias diversas. $\mathrm{O}$ interesse principal atualmente é prevenir e contornar essas complicações. ${ }^{1}$

No período pós-transplante de fígado, são realizadas biópsias para investigar as condições do enxerto, através da pesquisa de sinais de rejeição, danos ou obstrução nos ductos biliares, infecção viral, recorrência da doença de base e danos induzidos por drogas. O resultado da biópsia pode auxiliar na tomada de decisões clínicas, como a retirada da imunossupressão e outras intervenções. ${ }^{2}$ 
Embora tenha valor diagnóstico, a coleta do material apresenta riscos inerentes a intervenções cirúrgicas invasivas. As complicações da biópsia de fígado mais comuns são: dor local e reação vasovagal. Dentre as complicações mais graves, está a hemorragia. Raramente, podem ainda ocorrer pneumotórax, hemotórax, peritonite de bile, perfuração de órgãos, hemobilia e neuralgia. ${ }^{2}$

Apesar do desenvolvimento de técnicas menos invasivas como a ecografia e ressonância magnética, permanece a importância da biópsia devido às informações únicas obtidas através desta. Além de auxiliar o diagnóstico e acompanhamento das anormalidades hepáticas, a biópsia de fígado tornou-se também uma ferramenta para avaliar o prognóstico nos casos de rejeição crônica, hepatite $\mathrm{C} e$ fibrose progressiva do enxerto. ${ }^{1,2}$

Considerados os diferentes diagnósticos e alterações detectadas pelas biópsias, julgou-se importante traçar o perfil desses achados entre os pacientes acompanhados pelo serviço de transplante hepático e as principais alterações e suas correlações com a clínica, para melhor assistir os pacientes no pós-transplante hepático pediátrico.

\section{MÉTODOS}

Trata-se de um trabalho quantitativo de caráter exploratório descritivo. Foi realizada uma pesquisa documental, com revisão de prontuários e laudos de biópsia, mantidos pelo serviço de transplante de fígado de um hospital pediátrico de grande porte.

Foram coletados os dados dos laudos de biópsia, dados clínicos e marcadores hepáticos no pós-transplante. Os laudos de biópsia foram avaliados com relação aos critérios de indicação e alterações relatadas. Os achados microscópicos foram categorizados em: inflamação, fibrose, colestase, rejeição e esteatose e classificados entre ausente, indeterminado, discreto, moderado ou acentuado, conforme descrição em laudo.

Foram incluídos os pacientes em acompanhamento pela equipe de transplante no ano de 2013 e que foram submetidos à biópsia hepática ao longo do período póstransplante entre junho de 2000 até dezembro de 2013. Excluíram-se os participantes transferidos de outros serviços de transplante para acompanhamento. Os laudos de biópsia consultados foram todos emitidos pelo Centro de Patologia de Curitiba.

Os dados obtidos foram processados e analisados com o auxílio da ferramenta Excel $2010^{\circ}$. Realizou-se a análise descritiva dos achados, obtenção de médias e proporções considerando as variáveis de tempo de transplante, idade do paciente, peso e marcadores laboratoriais.

\section{RESULTADOS}

Inicialmente, realizou-se a triagem de 94 pacientes, onde 53 apresentaram registros de pelo menos uma biópsia hepática no pós-transplante; 28 com apenas uma biópsia; 13 com duas; 10 com três a cinco; um paciente com seis e o outro com sete biópsias.

Entre os 53 pacientes, a principal patologia que levou ao transplante foi a atresia das vias biliares, que ocorreu em $30(56,6 \%)$ pacientes. Outras patologias incluíram a cirrose criptogênica $(9,4 \%)$, hepatite A $(9,4 \%)$, doença autoimune $(3,8 \%)$, tumores hepáticos (5,7\%), síndrome de Alagille, deficiência de al antitripsina e galactosemia que somaram sete casos $(13,2 \%)$.

A idade dos pacientes na data do transplante variou de cinco meses a dezessete anos, com mediana de treze meses de idade. Na data do transplante, 21 (38.6\%) dos pacientes eram menores de um ano, 15 (28.9\%) apresentavam entre um e quatro anos, 10 (19.3\%) entre quatro e dez anos e sete (13.3\%) eram maiores de dez anos.

O peso variou de 6 a $60 \mathrm{~kg}, 16.7 \%$ dos pacientes pesavam abaixo de $7 \mathrm{~kg} ; 28.6 \%$ entre 7 e $10 \mathrm{~kg} ; 16.7 \%$ entre 10 e $20 \mathrm{~kg}$ e $21,4 \%$ acima de $20 \mathrm{~kg}$. Do total de transplantes incluídos no estudo cerca de $80 \%$ foram intervivos e $20 \%$ de doador falecido.

\section{Biópsias}

Um total de 105 laudos de biópsia hepática foi consultado para realização deste estudo. Dentre os laudos analisados, o tempo entre o transplante e a biópsia variou de sete dias até 11 anos, com a maior parte das amostras obtidas em até dois anos de pós-transplante (57.1\%). Os principais critérios de indicação para a biópsia estão dispostos na Tabela 1.

Tabela 1 - Indicação de biópsia hepática pós transplante

\begin{tabular}{llc}
\hline Indicação & \multicolumn{2}{l}{ Frequência \% } \\
\hline Aumento de Transaminases & 60 & 57,1 \\
Hipótese de Rejeição & 25 & 23,8 \\
Acompanhamento/Protocolar & 25 & 23,8 \\
Lesão Biliar (Estenose, Obstrução, Dilatação) & 15 & 14,3 \\
Icterícia, aumento de bilirrubina & 9 & 8,6 \\
Suspeita de Hepatite & 4 & 3,8 \\
Outros (Ascite, Nódulos Hepáticos, Evolução & 4 & 3,8 \\
de biópsia anterior com alteração) & & \\
\hline
\end{tabular}

Os principais achados histológicos foram divididos entre: inflamação, rejeição, fibrose, colestase e esteatose, estão dispostos na Figura 1. Dentre as 105 biópsias, seis apresentaram amostra insuficiente/inadequada e apenas 15 amostras não apresentavam qualquer alteração. 
Figura 1 - Principais achados histológicos

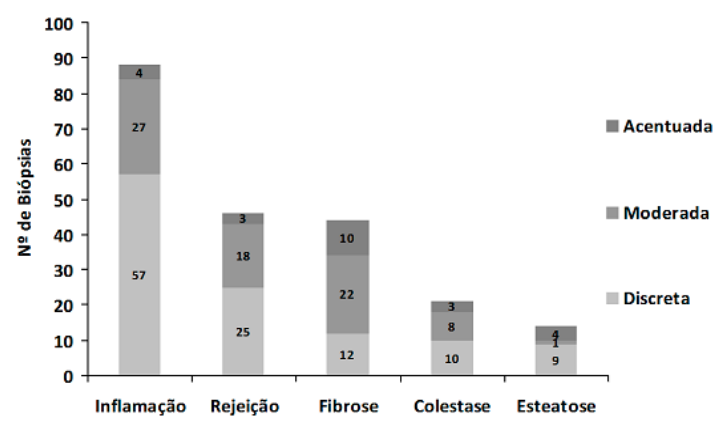

\section{Achados Inflamatórios}

Os achados inflamatórios foram relatados em $87 \%$ das biópsias; dentre essas, $54 \%$ relatavam inflamação discreta, $26 \%$ inflamação moderada e $4 \%$ inflamação acentuada. Dentre as amostras com inflamação, 52\% apresentaram característica de rejeição; em $46 \%$ delas havia rejeição discreta; em outras, $46 \%$ rejeição moderada e em $7 \%$ rejeição acentuada, conforme demonstrado na Figura 2. Sinais inflamatórios estavam presentes em 100\% das biópsias com rejeição.

Figura 2 - Inflamação / Rejeição

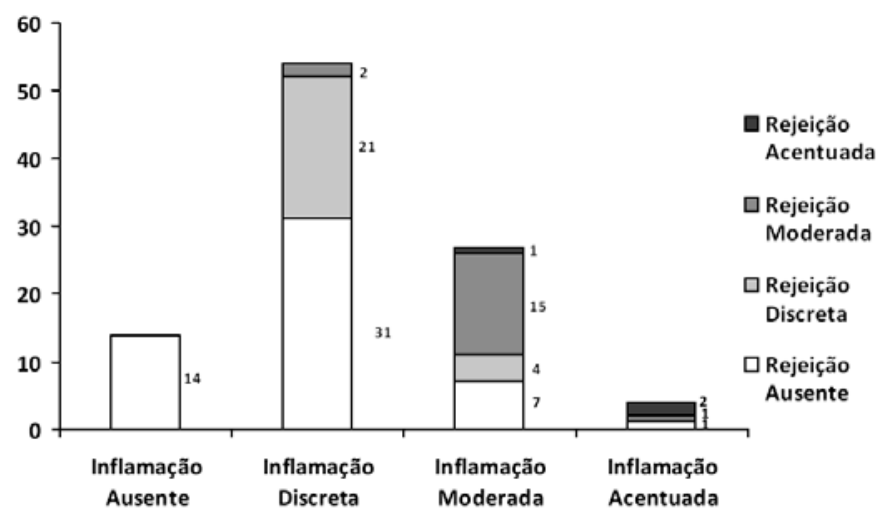

Parte dos laudos apresentava a categorização dos achados de rejeição pelos critérios de Banff. Essa é uma classificação padronizada pelos patologistas para avaliar a rejeição, que apresenta relação numérica, de acordo com a presença de sinais específicos no tecido. Os critérios de Banff foram considerados da seguinte forma: Escore entre 3/9 e 4/9 como rejeição discreta, entre $5 / 9$ e $6 / 9$ como rejeição moderada, entre 7/9 e 8/9 como rejeição acentuada; outros valores não foram observados.

\section{Fibrose}

Achados de fibrose portal foram relatados em $47.2 \%$ dos laudos; dentre esses, $29 \%$ apresentaram fibrose grau 1;
$48 \%$ fibrose grau 2 e $24 \%$ fibrose grau 3; sete também apresentavam sinais de rejeição aguda moderada ou acentuada.

Dentre as 49 biópsias colhidas com menos de 12 meses de transplante, apenas oito apresentavam algum grau de fibrose e com um caso de fibrose acentuada associada à rejeição aguda moderada. Das 26 biópsias colhidas entre um e três anos de transplante, foi relatada fibrose em 16 laudos. No período de três até 11 anos de transplante, foram 30 biópsias, das quais 21 apresentavam fibrose conforme demonstrado na Tabela 2.

Dos nove casos em que foi relatada fibrose acentuada, a média de tempo a partir do transplante, foi de 54 meses, enquanto que o restante da amostra apresentou média de aproximadamente 25 meses.

Com relação à evolução dos pacientes com fibrose, mesmo nos casos em que a fibrose foi considerada acentuada, houve boa evolução, porém com gradativo aumento das transaminases. Na comparação das médias com e sem fibrose houve um discreto aumento da ALT no grupo com fibrose (média 70.53 e 52.17), porém, devido ao elevado desvio padrão, não foi possível comprovar diferença estatística com esta análise.

Tabela 2- Tempo de transplante e Fibrose

\begin{tabular}{lcccc}
\hline $\begin{array}{l}\text { Tempo de } \\
\text { Transplante } \\
\text { (em meses) }\end{array}$ & $\begin{array}{c}\text { Biópsias com } \\
\text { fibrose }\end{array}$ & $\begin{array}{c}\text { No de } \\
\text { Pacientes }\end{array}$ & $\begin{array}{c}\text { Total de } \\
\text { Biópisas }\end{array}$ & $\%$ \\
\hline$<=12$ & 8 & 8 & 49 & 16,3 \\
$>12 \mathrm{a}<36$ & 16 & 14 & 26 & 61,5 \\
$>36$ & 21 & 14 & 30 & 70 \\
\hline
\end{tabular}

\section{Colestase, esteatose e outros achados}

Colestase foi relatada em $20 \%$ das amostras, $9.5 \%$ casos foram descritos como discreta, 7.6\% moderada e 3\% como colestase acentuada. Dentre os transplantes com mais de um ano, foi levantada uma proporção de $19.6 \%$ de colestase, para menos de um ano de transplante; esse valor chegou a $20.4 \%$ das biópsias. Portanto, não foi demonstrada correlação temporal quanto à colestase.

A proliferação ductular esteve presente em 11 amostras; sete delas também apresentavam colestase e sete indicavam rejeição de discreta a acentuada; em quatro casos houve associação entre rejeição e colestase, em cinco casos houve associação entre proliferação ductular e fibrose. Inflamação apareceu em todos os casos.

Dentre os 11 pacientes com proliferação ductular, oito tiveram estenose das vias biliares. Foi observada rejeição crônica em um paciente e foi necessário re-transplante 
posterior. Hipertensão portal foi relatada em um paciente, um caso de infecção viral por Vírus EpsteinBarr e Citomegalovírus, um caso de trombose da artéria hepática e um caso sem outras complicações além de inflamação.

Foram encontrados apenas 14 laudos com esteatose; um caso esteve relacionado com achados de rejeição aguda discreta e fibrose. Esteatose macrogoticular maciça foi citada em pelo menos três laudos e em um deles teve relação com obstrução biliar. Em cinco casos havia a presença de esteatose e fibrose. Em um caso foi relatada trombose da veia hepática, na qual ocorreu necrose coagulativa.

O enxerto hepático foi considerado preservado em 15 (14.3\%) dos 105 laudos; dentre esses, seis pacientes apresentaram aumento de enzimas hepáticas e cinco fizeram biópsia por protocolo. Desse grupo, apenas um paciente desenvolveu rejeição em biópsias posteriores. Entre as 22 biópsias com indicação protocolar, apenas cinco (22.7\%) apresentaram resultado sem alterações histológicas.

\section{DISCUSSÃO}

$\mathrm{Na}$ amostra analisada, encontrou-se alta proporção de anormalidades histológicas; foi relatada inflamação em mais de $84 \%$ dos laudos, e fibrose em $47 \%$. De fato, apenas $14.3 \%$ dos resultados de biópsia de fígado foram classificados como preservados. Tais achados corroboram com o que foi descrito em literatura, onde o percentual de alterações variou de 61 a 97\% entre biópsias no póstransplante pediátrico. ${ }^{3}$ No entanto, deve-se ressaltar que na amostra descrita não houve indicação regular de biópsias por protocolo. Uma proporção de $24 \%$ dos laudos avaliados referia-se às biópsias como sendo por protocolo ou acompanhamento e não como consequência de alteração de outros marcadores funcionais do enxerto.

A colestase foi encontrada em 21 biópsias; dessas, sete apresentavam também proliferação ductular, contra apenas três nas 78 restantes, sugerindo que tal achado pode estar associado a eventos colestáticos e corrobora com o descrito na literatura; a proliferação ductular e os tecidos regenerativos são incomuns nos tecidos em rejeição aguda, porém comuns em eventos relacionados à árvore biliar. ${ }^{4} \mathrm{As}$ colestases distribuíram-se de forma similar nas biópsias, tanto recentes ao transplante, quanto nas posteriores.

Houve notável aumento de fibrose em relação ao tempo de transplante na população descrita; esse fenômeno já foi reportado em outros trabalhos e tem grande incidência em pacientes pediátricos. ${ }^{5-7}$ Os motivos que levam a essa deterioração progressiva do enxerto, ainda não estão totalmente esclarecidos. Tais achados têm sido atribuídos a uma relação complexa, envolvendo fibrose, presença de auto-anticorpos no parênquima e hepatite auto-imune. ${ }^{6} \mathrm{~A}$ fibrose na região centrilobular nos enxertos pediátricos em longo prazo foi descrita em literatura e até onde se sabe atualmente, tem pouca relevância no prognóstico, não estando associada à infecção viral nem à rejeição crônica. ${ }^{5}$

Com a evolução dos métodos de imunossupressão, houve diminuição das complicações de rejeição celular aguda e rejeição crônica no curto prazo, porém há maior número de pacientes que apresentam rejeição aguda tardia e doença recorrente. ${ }^{8}$ A soma entre imunossupressão de longo prazo e reativação de doenças de base produz quadros histológicos complexos e consequências significativas com relação à fibrose e progressão para cirrose. ${ }^{8}$

Apesar de a etiologia ser desconhecida, estudos apontam que a patogenia está ligada à presença de anticorpos contra tecidos no enxerto, tais como células epiteliais biliares e hepatócitos. ${ }^{9}$ A fibrose no entorno da veia central é descrita como um evento recorrente em transplantes pediátricos intervivos e estudos realizados por imunohistoquímica sugerem que tenha relação com a resposta humoral. ${ }^{10}$ Embora as biópsias continuem sendo a principal ferramenta para avaliar a fibrose hepática, as pesquisas recentes buscam meios não invasivos de fazer essa avaliação ou contribuir com os diagnósticos, tais como a elastografia transiente e a interpretação de resultados laboratoriais como a razão entre AST/ALT e a razão entre o aspartato e contagem plaquetária. ${ }^{11,12}$

Com relação à indicação de biópsias protocolares, a literatura apresenta resultados que falam contra e a favor à sua realização. ${ }^{11,13}$ Nos resultados obtidos por este, destacou-se que, das 22 biópsias com indicação protocolar, apenas cinco $(22.7 \%)$ apresentaram resultado sem alterações histológicas. Dentre as alterações encontradas nesse grupo, constaram sinais de inflamação, rejeição e fibrose.

A biópsia protocolar pode detectar alterações e levar à mudança na estratégia de tratamento, seja no gerenciamento da imunossupressão ou no rigor do acompanhamento de exames. Em se tratando de pacientes que utilizam baixa imunossupressão, tal afirmação é corroborada. Em um estudo, foi encontrada alta prevalência de anormalidades histológicas em pacientes com marcadores aparentemente saudáveis, e por essa razão foi feita intervenção com imunossupressores, a fim de diminuir o risco de perda de função do órgão. ${ }^{13}$ No entanto, carecem ainda estudos que possam mensurar a efetividade terapêutica desse tipo de medida.

O critério ao se realizar ou não a biópsia periodicamente é controverso, pois deve ser considerado tratar-se de procedimento invasivo, passível de riscos. ${ }^{2} \mathrm{Tal}$ procedimento poderia ser melhor embasado com a definição de critérios para indicação, baseados no risco de recorrência da doença e de parâmetros de controle. 


\section{CONCLUSÃO}

As anormalidades em biópsia são comuns no póstransplante pediátrico e, em muitos casos, não apresenta forte correlação clínica. Por esse motivo, deve ser conduzida uma avaliação criteriosa para sua correta interpretação.

Deve-se dar atenção especial ao aumento de fibrose ao longo do pós-transplante; embora seja um achado comum nessa população, pode estar associado à rejeição crônica.

São necessários mais estudos quanto à indicação de biópsia protocolar para avaliação da fibrose e da rejeição, pois houve vantagem na deteç̧ão precoce de anormalidades histológicas. Permanece a importância da sua indicação nas condições de marcadores de função hepática alterados.

\section{ABSTRACT}

Introduction: Liver biopsies are performed to assess post transplant issues that may affect allograft function. There are points to be clarified as to the occurrence of histological alterations in the pediatric population and their meaning. Purpose: Analyze findings in post-transplant liver biopsy in pediatric patients at our service. Methods: An assessment of our pediatric liver transplant service records with patients being followed-up in December 2013. Histological findings were classified as inflammation, fibrosis, rejection, cholestasis and steatosis. Indications and correlation of those findings were described. Results: 105 post transplant liver biopsies in 53 patients were described. The most common findings were inflammation (87\%) and portal fibrosis (47.2\%). A survey of the fibrosis occurrence was detected related to the after transplantation period. Ductular proliferation was associated with serious complications. Among the protocol biopsies, 77.3\% showed abnormal findings such as fibrosis, inflammation, rejection and cholestasis., protocol liver biopsies and progressive allograft fibrosis were discussed. Conclusion: Histological abnormalities are common in these patients, even with no strong clinical correlation. Increase in allograft fibrosis occurrence over time was observed. Further studies need to assess indications of the liver biopsy protocol.

Keywords: Liver Transplantation, Biopsy; Pediatrics.

\section{REFERÊNCIAS}

1. Spada M, Riva S, Maggiore G, Cintorino D, Gridelli B. Pediatric liver transplantation. World J Gastroenterol, 2009,15(6):648-74.

2. Ovchinsky N, Moreira RK, Lefkowitch JH, Lavine JE. Liver biopsy in modern clinical practice: a pediatric point-of-view. Adv Anat Pathol 2012;19(4):250-62.

3. Hübscher S. What does the long-term liver allograft look like for the pediatric recipient? Liver Transpl. 2009 Nov; 15 Suppl. 2: S19-24.

4. Adeyi O, Fischer SE, Guindi M. Liver allograft pathology: approach to interpretation of needle biopsies with clinicopathological correlation. J Clin Pathol. 2010 Jan; 63(1):47-74.

5. Martin SR, Russo P, Dubois J, Alvarez F. Centrilobular fibrosis in longterm follow-up of pediatric liver transplant recipients. Transplantation. 2002 Set 27;74(6):828-36.
6. Evans HM, Kelly DA, McKiernan PJ, Hübscher S. Progressive histological damage in liver allografts following pediatric liver transplantation. Hepatology. 2006 Mai;43(5):1109-17.

7. Ekong UD, Melin-Aldana H, Seshadri R, Lokar J, Harris D, Whitington $\mathrm{PF}$, et al. Graft histology characteristics in long-term survivors of pediatric liver transplantation. Liver Transpl. 2008 Nov;14(11):1582-7.

8. Shetty S, Adams DH, Hubscher SG. Post-transplant liver biopsy and the immune response: lessons for the clinician. Expert Rev Clin Immunol. 2012 Set;8(7):645-61.

9. Nagai S, Ito $M$, Kamei $H$, Nakamura $T$, Ando $H$, Kiuchi T. Indirect immunohistochemical evaluation of graft fibrosis and interface hepatitis after pediatric liver transplantation. Pediatr Transplant. 2010 Mai;14(3):342-50. 
Perfil de biópsia hepática em pacientes em acompanhamento pós-transplante de fígado em um hospital pediátrico

10. Yamada H, Kondou H, Kimura T, Ikeda K, Tachibana M, Hasegawa Y, et al. Humoral immunity is involved in the development of pericentral fibrosis after pediatric live donor liver transplantation. Pediatr Transplant. 2012 Dez;16(8): 858-65.

11. Sanai FM, Keeffe EB. Liver biopsy for histological assessment: The case against. Saudi J Gastroenterol; 2010 Apr;16(2):124-32.
12.Alswat KA, Mumtaz K, Jafri W. Liver biopsy for histological assessment: The case in favor. Saudi J Gastroenterol. 2010 Apr;16(2):133-9.

13.Briem-Richter A, Ganschow R, Sornsakrin M, Brinkert F, Schirmer J, Schaefer H, et al. Liver allograft pathology in healthy pediatric liver transplant recipients. Pediatr Transplant. 2013 Set;17(6):543-9.

\section{Reconhecimentos}

Reconhecemos o auxílio prestado pela Dra. Elizabeth Schneider Gugelmin e equipe do serviço de patologia do

Hospital Pequeno Príncipe, na análise dos tecidos e nas idéias sugeridas para a complementação deste trabalho. 